\title{
Nano-Encapsulation of Plant Growth-Promoting Rhizobacteria and Their Metabolites Using Alginate-Silica Nanoparticles and Carbon Nanotube Improves UCB1 Pistachio Micropropagation
}

\author{
Mojde Moradi Pour ${ }^{1}$, Roohallah Saberi-Riseh ${ }^{2 *}$, Reza Mohammadinejad ${ }^{3,4}$, and Ahmad Hosseini ${ }^{5}$ \\ ${ }^{1}$ Department of Plant Protection, Faculty of Agriculture, Vali-e-Asr University of Rafsanjan 7718897111, Iran \\ ${ }^{2}$ Department of Plant Protection, Faculty of Agriculture, Vali-e-Asr University of Rafsanjan 7718897111, Iran \\ ${ }^{3}$ NanoBioEletrochemistry Research Center, Bam University of Medical Sciences, Bam, Iran \\ ${ }^{4}$ Student Research Committee, School of Medicine, Bam University of Medical Sciences, Bam, Iran \\ ${ }^{5}$ Department of Plant Protection, Faculty of Agriculture, Vali-e-Asr University of Rafsanjan 7718897111, Iran
}

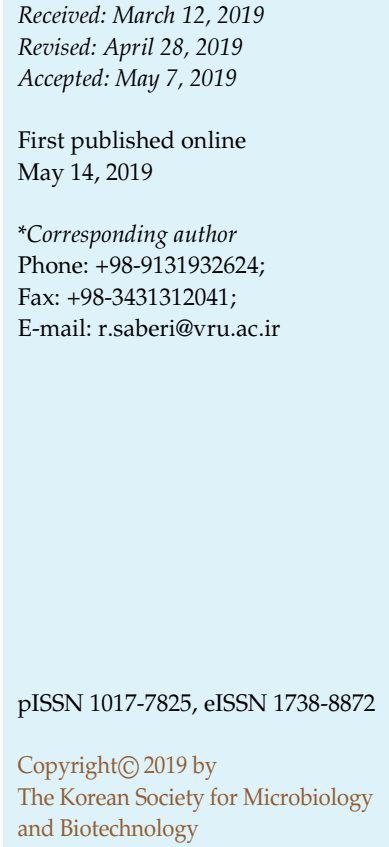

UCB-1 is the commercial rootstock of pistachio. Reproduction of this rootstock by tissue culture is limited by low levels of proliferation rate. Therefore, any compound that improves the proliferation rate and the quality of the shoots can be used in the process of commercial reproduction of this rootstock. Use of plant growth-promoting bacteria is one of the best ideas. Given the beneficial effects of nanoparticles in enhancement of the growth in plant tissue cultures, the aim of the present study was to investigate the effects of nanoencapsulation of plant growth-promoting rhizobacteria (using silica nanoparticles and carbon nanotubes) and their metabolites in improving UCB1 pistachio micropropagation. The experiment was conducted in a completely randomized design with three replications. Before planting, treatments on the DKW medium were added. The results showed that the use of Pseudomonas fluorescens VUPF5 and Bacillus subtilis VRU1 nanocapsules significantly enhanced the root length and proliferation. The nanoformulation of the VUPF5 metabolite led to the highest root length $(6.26 \mathrm{~cm})$ and the largest shoot $(3.34 \mathrm{~cm})$. Inoculation of explants with the formulation of the metabolites (both bacterial strains) significantly elevated the average shoot length and the fresh weight of plant compared to the control. The explants were dried completely using both bacterial strains directly and with capsule coating after the three days.

Keywords: Carbon nanotube, $\mathrm{SiO}_{2}$ nanoparticle, PGPR, UCB1, micropropagation

\section{Introduction}

Agricultural sector is one of the most important economic sectors in developing countries. The high nutritional value of pistachio has increased its consumption in different parts of the world. In the last decade, due to increased pistachio cultivation in the world and the variety of pistachios introduced in the world market, there has been a sharp competition between exporting countries [1]; therefore, to maintain the global position of pistachio, Iran has to increase the yield per unit area. To do this, we must provide good conditions for producing the maximum yield per unit area by conducting useful research and proper management in the gardens. Considering that reproduction of pistachios is often done by sexual and seeding, and subsequently the dissociation of traits occurs in the plants [2], it is possible to select plants that are resistant to climatic conditions, pests, and diseases, and to maintain superior traits as well as the rapid proliferation of compacted species using tissue culture technique [3]. Bacterial contaminations, severe browning of fine specimens, branch burns, and low growth of stems in addition to low efficacy in the shredding and rooting stage are all problems that Guardian and Alderson, as the first people in the field of pistachio 
tissue culture, have researched extensively [4]. Designing a dedicated environment can be the best way to solve these problems. Undoubtedly, the elements of culture medium are the most important factors in tissue culture [5]. The use of soil microorganisms in the production of bio-fertilizers has developed over decades. Today, bio-fertilizers are used in different formulations for different agricultural products and their importance is increasing every day, but very little information is available about the use of these organisms in in vitro studies, including plant tissue culture. Few reports exist regarding the use of plant growth-promoting bacteria in plant tissue culture. Through of Pseudomonas sp. in seedlings obtained from potato tissue culture, the root number, root dry weight, and stem length were improved [6]. del Carmen et al. [7] observed that the use of Bacillus spp. on the seedlings of tissue culture of banana improves the growth and concentration of nutrients in the leaves. These bacteria, when interacting with plants, can stimulate growth and plant health through several mechanisms, including nitrogen fixation and phytohormone production [8]. The main phytohormonic indole acetic acid produced by Pseudomonas and Bacillus bacteria has been found to be the most important phytohormone in plant growth regulation and root initiation. The use of artificial hormones partially or completely can be reduced by approaches that are commonly used in culture media. The synthesis and release of phenolic compounds, yellowishness and burns of the end of the shoots, with difficult and rough growth of rooting caused the proliferation of the UCB1 pistachio that is nowadays considered to be in serious trouble [9]. This base is resistant to cold and soil diseases (such as Verticillium, gummosis and nematodes) and has rapid growth [10]. There are several hypotheses for tip burning but Boron deficiency [11] and especially calcium are the most important ones. Researchers have always been looking for new combinations to address this problem. Today, nanotechnology plays a significant role in electronics, agriculture, medicine, energy, etc. [12-14]. The use of nanotechnology in agriculture, especially biotechnology and tissue culture, is very important and useful. Carbon nanotubes are one of several compounds used in different planting environments with different purposes. The control of yellowishness and plant cell proliferation is one of the most important applications of this combination [15]. Carbon nanotubes have been used in in vitro culture of plants such as tomatoes [16], carrots, lettuce and onions [17] and valuable results have been achieved. In vitro tissue cultures are in fact conducted under abnormal conditions. Lack of light, low $\mathrm{CO}_{2}$ concentration, lack of ventilation, ethylene accumulation and high concentrations of solutes used in the medium create stressful conditions. Therefore, tolerance of in vitro plants to stress conditions can improve growth and increase their rate of growth. The oxidized silicon nanostructure can form a double bar in the cell wall after absorption, increase plant resistance, and stimulate plant growth. By adding nano-silica fertilizer due to porosity and high cation exchange, $\mathrm{SiO}_{2}$ has been converted to monosiliclic acid. Monosilicic acid is the only plant-available silicon compound [18]. Enough uptake of monosilicic acid by the plant is important because silicon confers advantageous effects on plants [19, 20]. Despite the numerous reports of successful micronutrient studies, further research is needed on the selection of suitable culture media and the use of growth regulators to achieve optimal growth of explants. Antagonistic bacteria play an important role in the biocontrol of pathogens through various mechanisms, including the production of inhibitory substances from the growth of other microorganisms. The survival of the antagonist bacteria and providing the necessary conditions for the production of inhibitors at the right time and place are among the fundamental problems in a successful biocontrol. Providing a suitable method for the formulation of inhibitors, especially in cases where antibiotics are considered as the main mechanism of biocontrol, can solve the problems associated with the use of living bacteria. In this study, an intelligent Alginategelatin and nanoparticle (MWCNT, $\mathrm{SiO}_{2}$ ) system was designed as nano capsulations for antibacterial compounds by Pseudomonas fluorescent and Bacillus subtilis antagonist bacteria and their effect on the removal of environmental contamination of tissue culture, increased the rooting and proliferation and reduction of physiological complication.

\section{Experimental}

\section{Preparation of Plant Materials and Bacterial Strains}

UCB-1 pistachio and two strains of bacteria (Pseudomonas fluorescens VUPF5 and Bacillus subtilis VRU1) were used in this study. Bacterial strains were selected from the biological control collections of Vali-e-Asr University of Rafsanjan. All cultures were maintained at the Department of Biotechnology, Vali-e-Asr University of Rafsanjan, Iran.

\section{Microbial Cultures}

The strains VRU1 and VUPF5 were grown in King's medium B, and the medium was incubated at $28^{\circ} \mathrm{C}$ on an orbital shaker $(120 \mathrm{rpm})$ for $48 \mathrm{~h}$. Next, the number of viable bacteria per unit volume was counted by colony counting method. 


\section{Fermentations and Extracellular Metabolite Extraction}

Inoculum was prepared via cells from $24 \mathrm{~h}$ culture of two strains grown in $10 \mathrm{ml}$ of $\mathrm{KB}$ medium for 3 days at $30^{\circ} \mathrm{C}$ on a rotary shaker. Bacterial strains were grown and the metabolite was produced. Then, the fermentation broth was centrifuged at $13,000 \times g$ for $5 \mathrm{~min}$ where the supernatant was collected and filtered with a syringe $(0.2 \mu$, Millipore Corp.), and eventually passed once to ensure no bacteria were present. In this way, a culture medium containing metabolites without any bacteria cells was prepared [21].

\section{Plant Growth-Promoting Phytohormone Production}

Production of IAA by VUPF5 and VRU1 strains was measured by the method characterized by Patten and Glick [22]. In this test, each strain was cultured in nutrient broth medium and incubated for $24 \mathrm{~h}$ at $28^{\circ} \mathrm{C}$ on a rotary shaker (130 rpm). Then, $50 \mu \mathrm{l}$ of each bacterial strain suspension was added to nutrient broth including $50 \mu \mathrm{g} / \mathrm{ml}$ L-tryptophan. After $72 \mathrm{~h}$, the suspensions were centrifuged at 10,000 $\times g$ for $10 \mathrm{~min}$. Then, $2 \mathrm{ml}$ of supernatant was

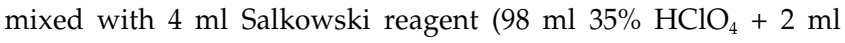
$0.5 \mathrm{M} \mathrm{FeCl}_{3}$ ). After $20 \mathrm{~min}$, the absorbance of the mixture was measured at $535 \mathrm{~nm}$ with a spectrophotometer.

\section{Preparation of Nanocapsules}

Preparation of nanocapsules was done based on the method of Tu et al. [23], with some modification. This was accomplished by adding a predefined amount of bacteria $\left(10^{10} \mathrm{CFU} / \mathrm{ml}\right)$ in $80 \mathrm{ml}$ of sterile sodium alginate $(2 \%)$, gelatin $(1.5 \%)$, concentration of $40 \mu \mathrm{g} / \mathrm{ml}$ carbon nanotubes, and $20 \mathrm{mM} \mathrm{SiO}_{2}$ nanoparticles. Next, we added $2 \mathrm{~g}$ of $\mathrm{CaCo}_{3}$ nanoparticles, then, twice the volume of soybean oil (continuous phase) comprising $2.5 \%(\mathrm{w} / \mathrm{v})$ and Span 80 were added into the homogenized solution under shaking with a mechanical stirrer for $15 \mathrm{~min}$. When the solution was uniform, $500 \mu \mathrm{l}$ of acetic acid was also added. After $15 \mathrm{~min}$ of stirring, and by adding $\mathrm{CaCl}_{2}$ nanoparticles, the process of encapsulation was completely performed. After centrifugation, the capsule beads were washed using $100 \mathrm{ml}$ of sterile physiological saline $(0.9 \%)$ and stored at $4{ }^{\circ} \mathrm{C}$. The same process was used for encapsulation of the bacterial metabolite, which was used instead of bacteria in the abovementioned protocol of bacterial metabolism [14].

\section{Preparation and Sterilization of Media}

Medium with modified DKW basal medium containing Gamborg's vitamins, 3\% sucrose $7 \mathrm{~g} / 1$ agar, $1 \mathrm{mg} / 1$ 6-benzyle adenine (BA), and $0.75 \mathrm{mg} / 1$ gibberellic acid (GA) was used for culture establishment. In vitro-derived shoots $(0.7-1 \mathrm{~cm}$ in length) of the UCB1 were micropropagated on a DKW proliferation medium. Initially, micro and macro stocks were made, and then the treatments were prepared and added to the medium (Table 1). Subsequently, relatively uniform explants were cultivated in the medium. The random experiment was conducted with three replicates, ten treatments and two samples per replicate (shoot tips about $10 \mathrm{~mm}$ long) were placed in each glass, where each
Table 1. Treatment during the test.

1. DKW $+10 \mathrm{mg}$ VUPF5 bacterial nanocapsules

2. DKW $+10 \mathrm{mg}$ VRU1 bacterial nanocapsules

3. DKW $+10 \mathrm{mg}$ VUPF5 metabolite nanocapsules

4. DKW $+10 \mathrm{mg}$ VRU1 metabolite nanocapsules

5. DKW $+80 \mu$ l VUPF5 bacteria

6. $\mathrm{DKW}+80 \mu \mathrm{l}$ VRU1bacteria

7. DKW $+80 \mu \mathrm{l}$ VUPF5 metabolite

8. DKW $+80 \mu \mathrm{l}$ VRU1 metabolite

9. DKW $+10 \mathrm{mg}$ nanocapsules without bacteria and metabolite 10. DKW (Control)

experiment was conducted. The experiment was monitored in terms of root growth and shoot development. Extended shoots (20-30 mm) with 2-3 nodes grown were selected to initiate the rooting stage. Two explants per glass were cultured on DKW for root induction. The cultures were incubated in a growth room with fluorescent lamps, $75 \mathrm{~W}$ at plant level, and a photoperiod of $16 \mathrm{~h}$ of light and $8 \mathrm{~h}$ of darkness at $26 \pm 2^{\circ} \mathrm{C}$. Factors such as shoot number per explant, shoot length, fresh weight, and root length were evaluated.

\section{Statistical Analysis}

The experiments were designed with a fully randomized design, and were analyzed via one-way ANOVA. SAS 9.1 (SAS Institute, Inc, USA) was used for data analysis and to compare means, with the analysis of variance (ANOVA) and the multiple comparison at $0.5 \%$ level.

\section{Results}

\section{Production of Auxin by Bacterial Strains}

In the present study, auxin (IAA) production was observed in two strains. The largest amount of produced auxin belonged to VRU1 which was $28.3 \mu \mathrm{g} / \mathrm{ml}$, while VUPF5 produced $19.3 \mu \mathrm{g} / \mathrm{ml}$. The results of this study indicated that use of nanoformulation of metabolites of both strains (VUPF5 and VRU1) in DKW medium in proliferation stage, growth rate for explants, and their volume biomass increased significantly.

According to ANOVA result, the number of shoots, shoot fresh weight, shoot length, and root length were significantly $(p<0.01)$ affected by nanoformulation of bacterial metabolites (Table 2).

The results revealed that the number of shoots produced in the treatments containing nano formulation of the metabolites of both bacterial strains increased compared to the control (Fig. 1). Hence, the shoot fresh weight also grew 
Table 2. ANOVA results of the effect of bacterial strains, bacterial metabolites and their nanoformulation on proliferation and root length of UCB-1 rootstock.

\begin{tabular}{lccccc}
\hline \multirow{2}{*}{ Source of variations } & \multirow{2}{*}{$\mathrm{DF}^{*}$} & \multicolumn{4}{c}{ Mean squares } \\
\cline { 3 - 6 } & & Number of shoots & Length of shoots & Fresh weight & Root length \\
\hline Treatment & 9 & $23.03^{* *}$ & $4.1^{* *}$ & $0.013^{* *}$ & $14.89^{* *}$ \\
Error & 20 & 0.26 & 0.001 & 0.000003 & 0.008 \\
CV\% & & 13.83 & 2.59 & 2.68 & 4.54 \\
\hline
\end{tabular}

* degrees of freedom

**significant $(p \leq 0.01)$

(Fig. 2). On the other hand, with addition of formulation containing bacteria on the third day after the culture, the explants died (Fig. 3). When using the bacteria directly and

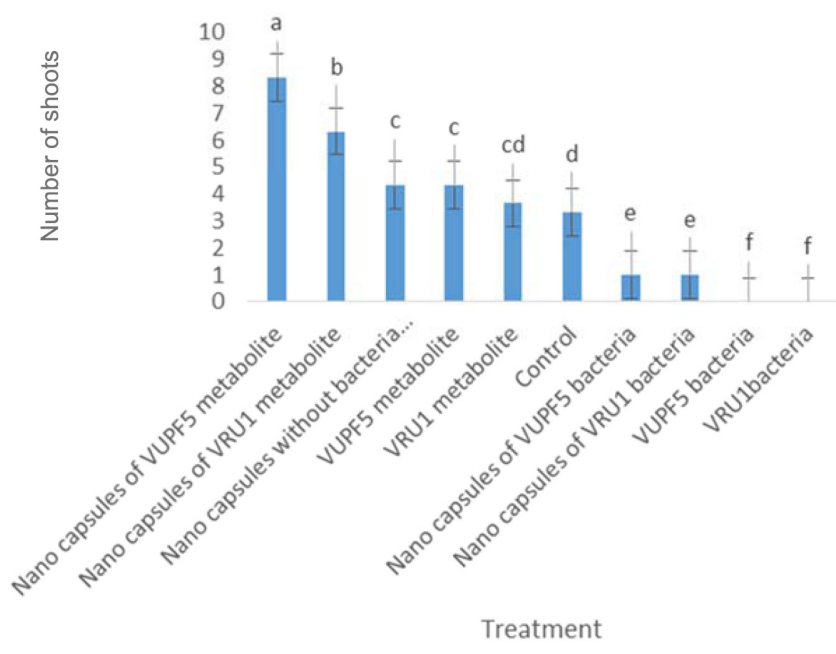

Fig. 1. The effects of bacterial strains, bacterial metabolites and their nanocapsules on the number of shoots of UCB-1.

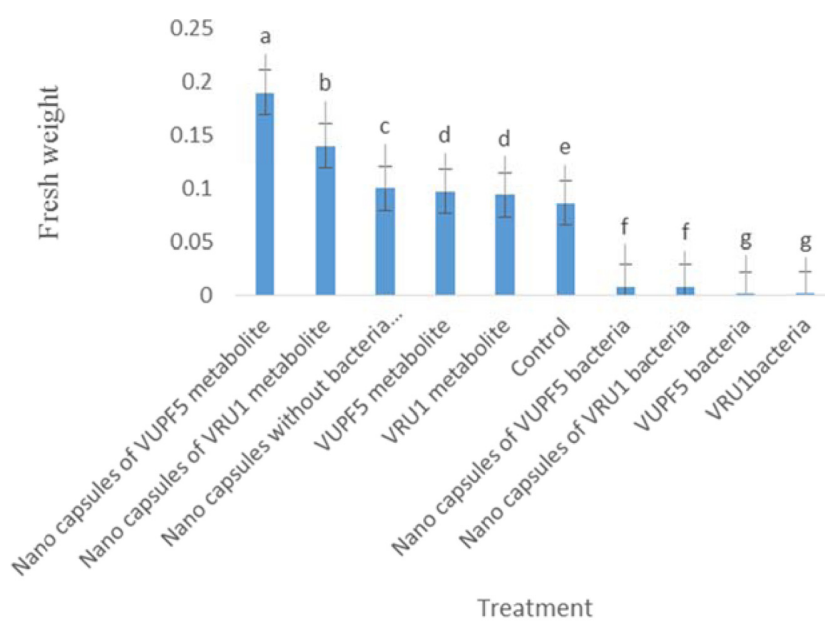

Fig. 2. The effects of bacterial strains, bacterial metabolites and their nanocapsules on the fresh weight of UCB-1. without capsule coating, the same results were obtained. In the treatment of metabolites (VUPF5 and VRU1) and formulation without bacteria and metabolites, there were no significant differences in the length and number of shoots. The pistachio explants inoculated alone either with Bacillus subtilis VRU1 directly or its nanocapsulation died after three days. Shoot fresh weight was significantly affected by encapsulation of bacterial metabolites (Fig. 4).

The results indicated that the shoot length of plants was affected by bacterial strains, bacterial metabolites, and their encapsulation. The highest and lowest shoot lengths in pistachio explants were observed in those inoculated with nanoencapsulation of VUPF5 metabolites and nanoformulation VRU1 bacteria, respectively. The explants treated with Pseudomonas fluorescents VUPF5 and its formulation did not experience any changes in the shoot length (Fig. 5).

The root length was significantly affected by nanoformulation of bacterial metabolites. After three weeks, a significant $(p<0.01)$ positive effect in root length $(6.26$ and $4.63 \mathrm{~cm}$ ) was observed in the treatment of nanocapsules of VUPF5 metabolites and nanocapsules of VRU1 metabolites than in the control. The results also indicated that bacterial strains and their capsulation applied alone inhibited the root growth (Figs. 6 and 7).

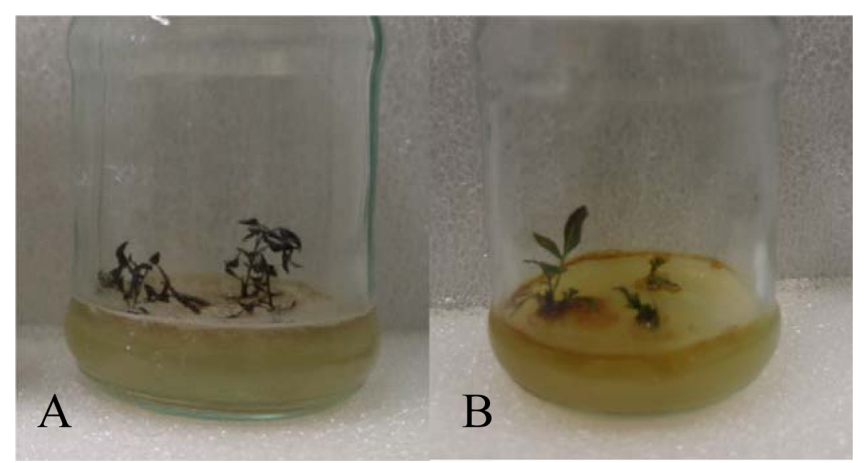

Fig. 3. (A) Nanoformulation of VRU1 bacteria. (B) Nanoformulation of VUPF5 bacteria. 


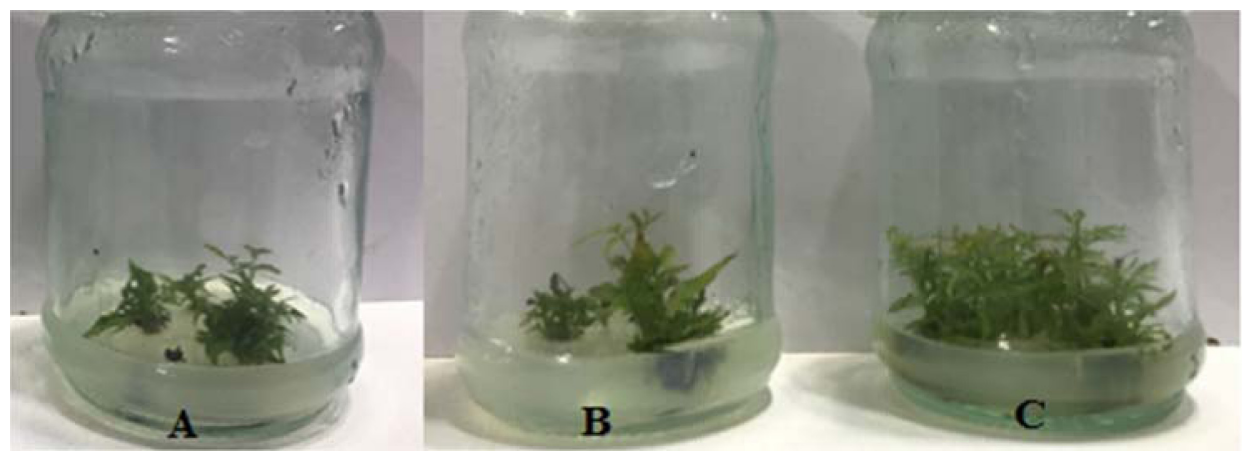

Fig. 4. The effects of treatment on proliferation of UCB-1.

(A) Control. (B) Nanoformulation of VRU1 metabolites. (C) Nanoformulation of VUPF5 metabolites.

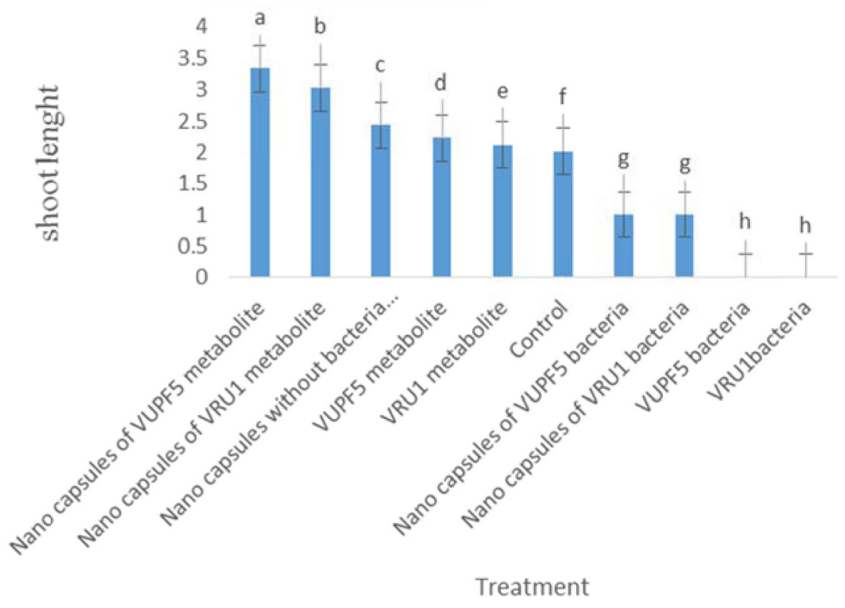

Fig. 5. The effects of bacterial strains, bacterial metabolites and their nanocapsules on the length of shoots of UCB-1.

\section{Discussion}

Increasing proliferation factor is economical for propagation. Increased rates of in vitro proliferation and

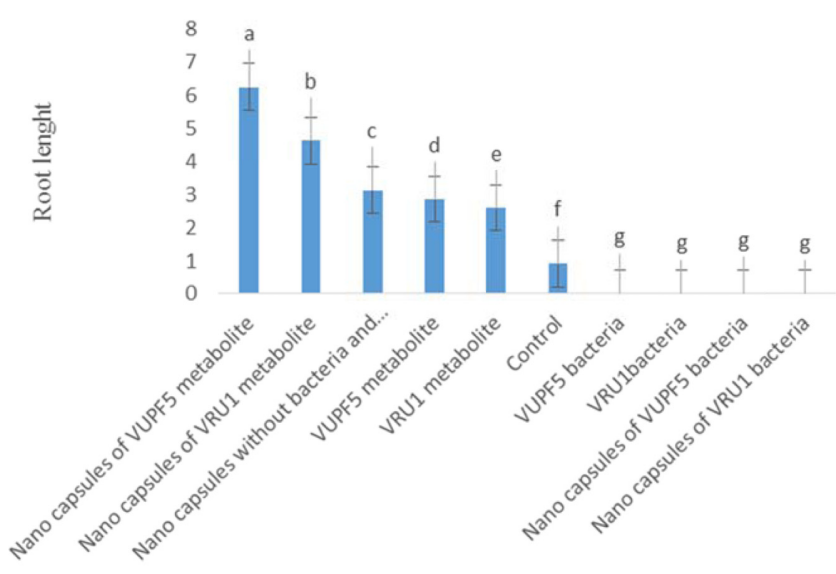

Treatment

Fig. 6. The effects of bacterial strains, bacterial metabolites and their nanocapsules on the root length of UCB-1.

production will help reduce production costs. Concentrations and the type of elements and compounds added to the medium influence the proliferation rate. Use of plant growth promoting bacteria for various plants as biofertilizers is

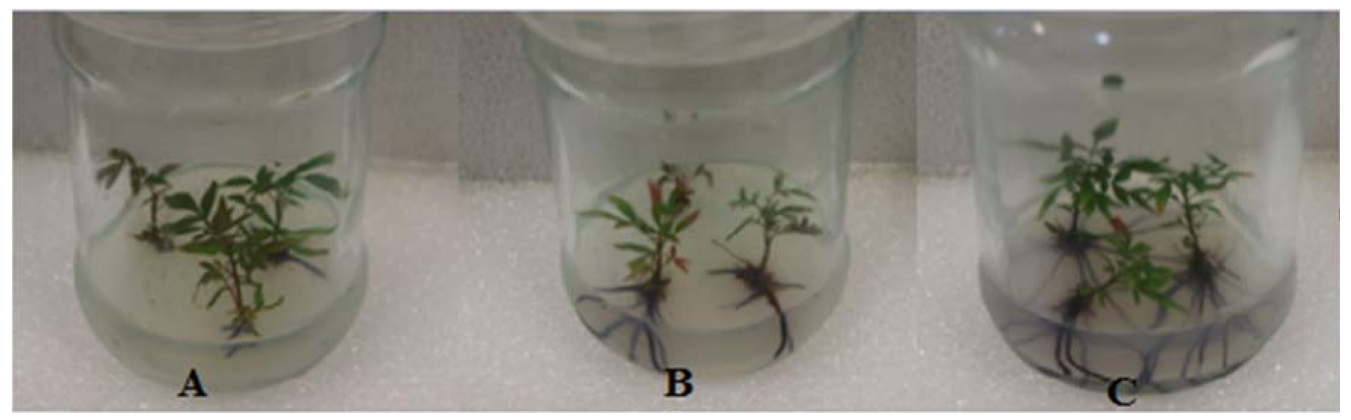

Fig. 7. The effects of treatment on rooting of UCB-1.

(A) Control. (B) Nanoformulation of VRU1 metabolites. (C) Nanoformulation of VUPF5 metabolites. 
increasingly becoming important, and extensive research is underway. Note that these microorganisms add a variety of materials to the environment. There is a possibility that there will be positive effects on the development of the tissue culture from the callus formation to the stage of transfer to soil. There are few reports in this field, and further research on this subject is necessary. There is information on the beneficial effects of microorganisms, including increasing rooting, improving growth, and reducing the vitrification in plant tissue culture [24]. Plant growth-promoting rhizobacteria that release a wide range of chemicals stimulate plant growth and induce resistance in plants [25]. Inoculation of plant tissue culture with these bacteria can be protected under many biotic and abiotic stresses $[26,27]$. In this experiment, according to the results obtained, it was observed that nanoencapsulation of bacterial metabolites was effective in enhancing proliferation of shoots and rooting of the UCB1 pistachio. This effect was seen in the formulation of the metabolites of both bacteria. Larraburu et al. [28] revealed that inoculation with bacteria in tissue culture promotes root development of micropropagation of Photinia. They showed that PGPR inoculated mixture with auxin would improve root organogenesis of micropropagated plants. In the present study, use of both bacteria directly and in nanocapsule coatings reduced the growth and number of leaves. This can be due to an increase in auxin levels and toxicity in the plant. The effect of plant growth-promoting rhizobacteria is not necessarily positive in all conditions and it should follow the treatments that have synergistic effects with bacteria. One of the nanoparticles used in the formulation in the current research was carbon nanotubes, whose use in various culture media led to an increase in proliferation rates. Further, Jackson et al. [29] and Mandol et al. [30] reported that high concentrations of nanotubes have no toxic effect on plants. Use of carbon nanotubes has a positive effect on cell function [31]. Carbon nanotubes also influenced the gene expression rate within the plant, which probably led to an increase in the proliferation rate. Khodakovskaya et al. [32] showed that use of multi-walled nanotubes on new shoots of tomato resulted in modification of gene expression. CNTs are also effective in increasing the shoots' elongation. Probably, as a growth regulator, it leads to a proliferation of cell division, causing the development of shoots. The effect of nanotubes on elongation growth was reported by Canas et al. [17], stating that the use of nanotubes in the culture medium would increase elongation in the roots of cabbage, lettuce, carrots, and tomato seeds. When using nanocapsules containing bacterial metabolites, the rate of shoot tip necrosis was reduced. This necrosis is believed to be because of the deficiency of nutrients with low mobility such as calcium and boron. The result of Liu et al. [33] suggested that CNT penetrates the cell wall and cell membrane of plants [34]. Carbon nanotubes also follow such a mechanism and increase dynamism as well as even zinc, calcium, and boron uptake. Recently, the role of Si in metabolism of plants has received a great deal of attention [35]. Many studies have indicated that Si is useful for plant growth, under a range of abiotic stress conditions [36]. Research has shown that the presence of silicon enhances the plant growth and crop yield. This is the effect of silicon due to the enhanced stem mechanical stability and leaves to absorb light and enhancing photosynthesis in plants [37]. The results revealed that nanostructured $\mathrm{SiO}_{2}$ treatments greatly increased seedling growth, root collar diameter, main root length, and improved seedling quality [38]. Researchers have shown that transpiration from leaves of several plants diminishes significantly through usage of $\mathrm{Si}$ [39]. The effects of silica oxide nanoparticles on the growth of Changbai larch seedlings were observed under different concentrations, main root length, and the number of lateral roots [38]. Effect of silicon on crop yield may be due to its deposition in the leaf area, leaf strength enhancement, and increased chlorophyll content per unit leaf area. It also enhances the plant's ability to use light absorption more efficiently. Donegá et al. [40] showed that silicon use amended the plant growth and enhanced photosynthesis. In oxidative damage, $\mathrm{Si}$ can defend the plant tissues affected by salt, and improve the growth of tomato plants in salt toxicity [41]. In the inoculated treatments with the desired formulation, greenness of plant was observed. One of the reasons for this is the presence of silicon nanoparticles in the formulation. Silicon prompts the levels of chlorophyll to rise [36]. Binding of CNT to other elements can result in improved uptake of themselves and available mineral elements in the culture medium [42]. Therefore, it is possible to increase proliferation and rooting of UCB1 pistachio in the treatment where the encapsulation of metabolism of both bacterial strains would increase the absorption of phytohormone, silica nanoparticles, and other elements that have been present in bacterial metabolite and culture media. Due to the important role of silica nanoparticles in plant growth and resistance, this nanoparticle was used in the capsule wall. The results of the current study indicated that the use of bacterial metabolites in nanocapsule formulation with nanoparticles whose effects on tissue culture were proven in previous studies was effective in increasing the growth 
and proliferation and improving elongation and rooting in tissue culture. This formulation is an effective method for the use of compounds producing plant growth-promoting rhizobacteria, which are useful for plant growth in coating degradable materials and nanoparticles, which are effective in increasing plant growth under tissue culture conditions.

\section{Acknowledgments}

The authors acknowledge Vali-e-Asr University of Rafsanjan for providing the research materials and funds.

\section{Conflict of Interest}

The authors have no financial conflicts of interest to declare.

\section{References}

1. Razavi SM, Emadzadeh B, Rafe A. Amini AM. 2007. The physical properties of pistachio nut and its kernel as a function of moisture content and variety: Part I. Geometrical properties. J. Food Eng. 81: 209-217.

2. Tilkat E, Süzerer V, Akdemir H, Ayaz Tilkat E, Ozden Çiftçi Y, Onay A. 2013. A rapid and effective protocol for surface sterilization and in vitro culture initiation of adult male pistachio (Pistacia vera L. cv."Atlı"). Academia J. Sci. Res. 1: 134-141.

3. Morfeine EA. 2013. Effect of anti-browning on initiation phase of Musa species grand naine in vitro. Forest. Prod. J. 2: 45-47.

4. Barghchi M. Alderson APG. 1983. In vitro Propagation of Pistachia vera L. from seedling tissues. J. Hortic. Sci. Biotechnol. 58: 435-445.

5. Vessey JK. 2003. Plant growth promoting rhizobacteria as biofertilizers. Plant Soil 255: 571-586.

6. Frommel MI, Nowak J. Lazarovits G. 1991. Growth enhancement and developmental modifications of in vitro grown potato (Solanum tuberosum spp. tuberosum) as affected by a nonfluorescent Pseudomonas sp. Plant Physiol. 96: 928936.

7. del Carmen Jaizme-Vega M, Rodríguez-Romero AS, Guerra MSP. 2004. Potential use of rhizobacteria from the Bacillus genus to stimulate the plant growth of micropropagated bananas. Fruits 59: 83-90.

8. Glick BR, Penrose DM. Ma W. 2001. Bacterial promotion of plant growth. Biotechnol. Adv. 19: 135-138.

9. Nezami SR, Yadollahi A, Hokmabadi H. Eftekhari M. 2015. Control of shoot tip necrosis and plant death during in vitro multiplication of pistachio rootstock UCB1 (Pistacia integrimax P. atlantica). J. Nuts. 6: 27-35.
10. Ferguson L, Beede R, Reyes H. Seydi M. California pistachio rootstock trials; 1989-2001. California Pistachio Ind. Annu. Rep. 19-24.

11. Mason G. Guttridge C. 1974. The role of calcium, boron and some divalent ions in leaf tipburn of strawberry. Sci. Hortic. 2: 299-308.

12. Oloumia H, Ahmadi Mousavib E. Mohammadi Nejad R. 2018. Multi-wall carbon nanotubes effects on plant seedlings growth and cadmium/lead uptake in vitro. Russ. J. Plant Physiol. 65: 260-268.

13. Ahmadi Z, Mohammadinejad Reza, Ashrafizadeh M. 2019. Drug delivery systems for resveratrol, a non-flavonoid polyphenol: Emerging evidence in las decades. J. Drug Deliv. Sci. Technol. 51: 591-604.

14. Moradi Pour M, Saberi-Riseh R, Mohammadinejad R, Hosseini A. 2019. Investigating the formulation of alginategelatin encapsulated Pseudomonas fluorescens (VUPF5 and T17-4 strains) for controlling Fusarium solani on potato. Int. J. Biol. Macromol. 133: 603-613.

15. Heydari HR. 2013. A study on application of carbon nanotubes (CNTs) as a plant growth regulator in Anthurium andreanum L. micropropagation, M.Sc. dissertation, faculty of agriculture, University of Tarbiat Modares. Iran. (In Farsi).

16. Khodakovskaya M, Dervishi E, Mahmood M, Xu Y, Li Z, Watanabe F, Biris AS. 2009. Carbon nanotubes are able to penetrate plant seed coat and dramatically affect seed germination and plant growth. ACS Nano 3: 3221-3227.

17. Cañas JE, Long M, Nations S, Vadan R, Dai L, Luo M, et al. 2008. Effects of functionalized and nonfunctionalized singlewalled carbon nanotubes on root elongation of select crop species. Environ. Toxicol. Chem. 27: 1922-1931.

18. Laane HM. 2018. The effects of foliar sprays with different silicon compounds. Plants 7: 45.

19. Ma JF, Yamaji N. 2006. Silicon uptake and accumulation in higher plants. Trends Plant Sci. 11: 392-397.

20. Deshmukh RK, Ma JF, Bélanger RR. 2017. Role of silicon in plants. Front. Plant Sci. 8: 1858.

21. Ramírez R, Arias M, David J, Bedoya JC, Rueda L, Antoni E, et al. 2015. Metabolites produced by antagonistic microbes inhibit the principal avocado pathogens in vitro. Agron. Colomb. 33: 58-63.

22. Patten CL, Glick BR. 1996. Bacterial biosynthesis of indole-3acetic acid. Can. J. Microbiol. 42: 207-220.

23. Tu L, He Y, Yang H, Wu Z., Yi L. 2015. Preparation and characterization of alginate-gelatin microencapsulated Bacillus subtilis SL-13 by emulsification/internal gelation. J. Biomater. Sci. Polym. Ed. 26: 735-749.

24. Mirza MS, Ahmad W, Latif F, Haurat J. Bally R, Normand P, et al. 2001. Isolation, partial characterization, and the effect of plant growth-promoting bacteria (PGPB) on micropropagated sugarcane in vitro. Plant Soil 237: 47-54.

25. Beneduzi A, Ambrosini A, Passaglia LM. 2012. Plant growth-promoting rhizobacteria (PGPR): their potential as 
antagonists and biocontrol agents. Int. J. Genet Mol. Biol. 35: 1044-1051.

26. Vestberg M, Kukkonen S, Saari K, Parikka P, Huttunen J, Tainio L, et al. 2004. Microbial inoculation for improving the growth and health of micropropagated strawberry. Appl. Soil Ecol. 27: 243-258.

27. Nowak J. Shulaev V. 2003. Priming for transplant stress resistance in in vitro propagation. In Vitro Cell. Dev. Biol. Plant 39: 107-124.

28. Larraburu EE, Carletti SM, Cáceres EAR. Llorente BE. 2007. Micropropagation of photinia employing rhizobacteria to promote root development. Plant Cell Rep. 26: 711-717.

29. Jackson P, Jacobsen NR. Baun A, Birkedal R, Kühnel D. Jensen KA, et al. 2013. Bioaccumulation and ecotoxicity of carbon nanotubes. Chem. Cent. J. 7: 154.

30. Mondal A, Basu R, Das S. Nandy P. 2011. Beneficial role of carbon nanotubes on mustard plant growth: an agricultural prospect. J. Nanopart. Res. 13: 4519.

31. Casey A, Farrell GF, McNamara M, Byrne HJ, Chambers G. 2005. Interaction of carbon nanotubes with sugar complexes. Synth. Met. 153: 357-360.

32. Khodakovskaya MV, de Silva K, Nedosekin DA, Dervishi E, Biris AS, Shashkov EV, et al. 2011. Complex genetic, photothermal, and photoacoustic analysis of nanoparticleplant interactions. Proc. Natl. Acad. Sci. USA 108: 1028-1033.

33. Liu Q, Chen B, Wang Q, Shi X, Xiao Z, Lin J, Fang X. 2009. Carbon nanotubes as molecular transporters for walled plant cells. Nano Lett. 9: 1007-1010.

34. Oloumi H, Mousavi E. Mohammadinejad R. 2014. Multiwalled carbon nanotubes enhance $\mathrm{Cd}^{2+}$ and $\mathrm{Pb}^{2+}$ uptake by canola seedlings. Agrochimica 58: 91-102.
35. Kaya C, Tuna L. Higgs D. 2006. Effect of silicon on plant growth and mineral nutrition of maize grown under waterstress conditions. J. Plant Nutr. 29: 1469-1480.

36. Silva O, Lobato A, Avila F, Costa R, Oliveira Neto C, Santos Filho B, et al. 2012. Silicon-induced increase in chlorophyll is modulated by the leaf water potential in two water-deficient tomato cultivars. Plant Soil Environ. 58: 481-486.

37. Samuels A, Glass A, Ehret D, Menzies J. 1993. The effects of silicon supplementation on cucumber fruit: changes in surface characteristics. Ann. Bot. 72: 433-440.

38. Bao-shan L, Chun-hui L, Li-jun F, Shu-chun Q, Min Y. 2004. Effect of TMS (nanostructured silicon dioxide) on growth of Changbai larch seedlings. J. For. Res. 15: 138-140.

39. Agarie S, Agata W, Uchida H, Kubota F, Kaufman PB. 1996. Function of silica bodies in the epidermal system of rice (Oryza sativa L.): testing the window hypothesis. J. Exp. Bot. 47: 655-660.

40. Silva ON, Lobato AKS, Ávila FW, Costa RCL, Oliveira Neto CF, Santos Filho BG, et al. 2012. Silicon-induced increase in chlorophyll is modulated by the leaf water potential in two water-deficient tomato cultivars. Plant Soil Environ. 58: 481486.

41. Al-aghabary K, Zhu Z. Shi Q. 2005. Influence of silicon supply on chlorophyll content, chlorophyll fluorescence, and antioxidative enzyme activities in tomato plants under salt stress. J. Plant Nutr. 27: 2101-2115.

42. Kermani SA, Hokmabadi H. Jahromi MG. 2017. The evaluation of the effect of multiwall carbon nano tube (MWCNT) on in vitro proliferation and shoot tip necrosis of pistachio rootstock UCB-1 (Pistacia integrima $\times$ P. atlantica). J. Nuts 8: 49-59. 